\title{
Effect of chemical refining on the quality of kenaf (hibiscus cannabinus) seed oil
}

\begin{abstract}
Crude kenaf seed oil was obtained by solvent extraction and chemically refined using industrial refining process, which includes degumming, neutralization, bleaching, and deodorization. The changes in physical characteristics, oxidation indexes, antioxidant activity, bioactive compounds, and fatty acid composition were determined after each stage of refining. The results obtained showed that there was no significant difference in the specific gravity of kenaf seed oil, but there was a significant increase in the refractive index and a significant decrease in the $\mathrm{a}^{*}$ and $\mathrm{b}^{*}$ values in the color determination after the refining. Peroxide value decreased from 2.64 to $0.55 \mathrm{meq} / \mathrm{kg}$, $\mathrm{p}$-Anisidine value increased from 2.41 to 3.41, TOTOX value decreased from 7.70 to 4.51 , and free fatty acids decreased from 1.72 to 0.61 after the whole refining process. There was a removal of $64.5 \%$ of total phenolic content, $65.3 \%$ of total carotenoid content, $22.5 \%$ of phytosterol content and high retention of tocopherol content in kenaf seed oil after refining. Kenaf seed oil showed an increasing of $84.5 \%$ and $58.6 \%$ in DPPH value and ABTS+ value, respectively. Oleic acid was found in the largest amount in the refined kenaf seed oil (35.1\%), followed by linoleic acid (32.3\%) and palmitic acid (21.9\%). There was a slight increase in unsaturated fatty acids and a slight decrease in saturated fatty acids after refining. This work showed that the chemical refining process offers an improvement in the quality of kenaf seed oil.
\end{abstract}

Keyword: Hibiscus cannabinus L.; Chemical refining; Oxidation indexes; Antioxidant activity; Bioactive compounds; Fatty acids 